\title{
QUALIDADE FISIOLÓGICA DE SEMENTES DE MILHO TRATADAS ASSOCIADAS A POLÍMEROS DURANTE O ARMAZENAMENTO
}

\author{
Performance of corn seeds treated with furazin and maxin \\ in association with polimers, during storage
}

\author{
Carlos Eduardo Pereira ${ }^{1}$, João Almir Oliveira² ${ }^{2}$ José Renato Emiliorelli Evangelista ${ }^{3}$
}

\begin{abstract}
RESUMO
O uso de produtos fitossanitários aplicados via sementes é uma prática rotineira para a cultura do milho. No entanto, a crescente preocupação com o meio ambiente e com a segurança humana torna necessário o desenvolvimento de tecnologias que venham reduzir os riscos com a manipulação destes fitoprotetores, sendo este um dos principais objetivos do uso de polímeros. Assim, com este trabalho, objetivou-se avaliar a qualidade fisiológica e sanitária de sementes de milho submetidas a tratamentos fitossanitários em associação com diferentes polímeros, durante o armazenamento. Para tanto, as sementes de milho dos híbridos AG9010 e AG122 foram tratadas ou não com inseticida carbofuran (nome comercial: Furazin) na dosagem de 1,5 L/100 kg de sementes e em mistura com o fungicida fludioxonil (nome comercial: Maxin) na dosagem de $100 \mathrm{~mL} / 100 \mathrm{~kg}$ de sementes. Durante o tratamento das sementes foram utilizados ou não os polímeros 1519 na dosagem de $50 \mathrm{~mL} / 100 \mathrm{~kg}$ de sementes e 1080 na dosagem de $100 \mathrm{~mL} / 100$ $\mathrm{kg}$ de sementes. As sementes foram acondicionadas em embalagens de papel multifoliado e armazenadas durante seis meses sob condições ambientais. A qualidade das sementes foi avaliada antes e após o armazenamento, por meio das seguintes determinações: teste de germinação, teste de frio, teste de emergência em bandeja, determinação de sementes infestadas, índice de velocidade de emergência e teste de sanidade. Conclui-se que a peliculização não afeta a qualidade fisiológica das sementes de milho e a aplicação de Furazin e/ou Maxin, sobre as sementes de milho, é tecnicamente viável. Sementes de milho de alta qualidade inicial podem ser tratadas e armazenadas por seis meses, sem que haja comprometimento de sua qualidade fisiológica.
\end{abstract}

Termos para indexação: Peliculização, Zea mays, inseticida, fungicida, fludioxonil, carbofuran.

\begin{abstract}
The use of phytosanitary chemicals applied via seeds is a routine practice for corn crop, nevertheless, the growing concern about environment and human security make it necessary to develop new technologies which can reduce the handling risks of these phytoprotectors, therefore, this is one of the main objectives of polymer use. Thus, this work was intended to evaluate the physiological and sanitary quality of corn seeds submitted to phytosanitary treatments in association with different polymers during storage. So, the corn seeds of the hybrids AG9010 e AG122 were treated or not with the insecticide carbofuran (Furazin) at the dosage of $1.5 \mathrm{~L} / 100 \mathrm{~kg}$ of seeds and in mixture with the fungicide fludioxonil (Maxin) at the dosage of $100 \mathrm{~mL} / 100 \mathrm{~kg}$ of seeds. Over the treatment of the seeds, polymers 1519 were utilized or not at the dosage of $50 \mathrm{~mL} / 100 \mathrm{~kg}$ of seeds, and polymer 1080 at the dosage of $100 \mathrm{~mL} / 100 \mathrm{~kg}$ of seeds. The seeds were packed into multifoliated paper packages and stored for six months under environmental conditions, seed quality being evaluated before and after storage by means of the following determinations: germination test, coiled test, tray germination test, infested seed determination, emergence velocity index and sanity test. It follows that pelliculation does not affect the physiological quality of corn seeds and the application of Furazin and/or Maxin upon corn seeds, is technically viable. Corn seeds of high initial quality may be treated and stored for six months, without any endangerment of their physiological quality.
\end{abstract}

Index terms: Pelliculation, Zea mays, insecticide, fungicide, fludioxonil, carbofuran.

(Recebido para publicação em 22 setembro de 2004 e aprovado em 4 de maio de 2005)

\section{INTRODUÇÃO}

O uso de produtos fitossanitários aplicados via sementes é uma prática rotineira para a cultura do milho, no entanto, a crescente preocupação com o meio ambiente e com a segurança durante o processo de manipulação dessas sementes tem aumentado a demanda por tecnologias de aplicação que permitam a redução dos riscos, sem que a qualidade das sementes seja comprometida.
O uso de polímeros para recobrimento de sementes, ou peliculização, é uma técnica recente que, inicialmente, foi adaptada a partir de materiais desenvolvidos para a indústria farmacêutica (TAYLOR et al., 2001). Dentre os benefícios da peliculização, observa-se uma melhor retenção dos produtos fitossanitários às sementes (MAUDE, 1998; SAMPAIO \& SAMPAIO, 1998; SILVEIRA, 1998; SMITH, 1997), garantindo que inseticidas, fungicidas, dentre outros, atuem onde realmente são necessários.

\footnotetext{
1 Pós-graduando - Mestrado em Fitotecnia - Universidade Federal de Lavras/UFLA - Cx. P. 3037 - $37200-000$ - Lavras, MG.

2 Professor Dr. da UFLA - Universidade Federal de Lavras/UFLA - Cx. P. 3037 - 37200-000 - Lavras, MG.

${ }^{3}$ Graduando do curso de Agronomia - Universidade Federal de Lavras/UFLA - Cx. P. 3037 - 37200-000 - Lavras, MG.
} 
Para sementes sensíveis a embebição em condições de baixa temperatura, a peliculização pode reduzir as injúrias causadas por esse processo (TAYLOR et al., 2001). O uso de polímeros pode, ainda, fornecer uma proteção adicional contra patógenos às sementes, além de garantir maior segurança durante o seu manuseio (ROBANI, 1994), sendo que, essa redução da exposição do homem aos produtos químicos tóxicos adicionados às sementes, é o principal impulsor do uso da técnica de peliculização (TAYLOR et al., 1998).

Rivas et al. (1998), estudando diferentes polímeros (Sacrust, Chitosan, Daran e Certop) aplicados sobre sementes de milho, não encontraram diferenças significativas entre eles, sobre a qualidade de sementes. Estes autores verificaram, ainda, que tanto a germinação como a emergência das plântulas não foi afetada pela aplicação dos polímeros. Também Lima et al. (2003b) observaram que os filmes de revestimento utilizados em sua pesquisa não prejudicaram a qualidade fisiológica de sementes de algodão. A peliculização, junto ao tratamento fungicida, pode aumentar a germinação de sementes de tomate para lotes de baixo vigor, não afetando a ação do fungicida sobre os fungos associados às sementes (LIMA et al., 2003a). No entanto, Duan \& Burris (1997), avaliando o uso de polímeros sobre sementes de beterraba observaram decréscimo na germinação de alguns cultivares.

Alves et al. (2003), trabalhando com sementes de feijoeiro, verificaram que a peliculização associada ao fungicida não interferiu na germinação e vigor das sementes e constataram que os polímeros utilizados apresentaram efeito diferenciado sobre a qualidade das sementes, sendo o D11519 superior em relação ao L1080. Da mesma forma, resultados obtidos por Clemente et al. (2003), mostram que a associação da película com fungicida não interferiu na qualidade fisiológica de sementes de feijão. Henning et al. (2003), estudando polímeros associados a fungicidas para o tratamento de sementes de soja, concluíram que os polímeros só devem ser empregados em conjunto com fungicidas, já que os mesmos não protegem as sementes no solo, resultando em baixa emergência de plântulas. Também Barros et al. (2002) e Lima et al. (2003c) concluíram que o filme utilizado para o revestimento não afetou a eficiência do tratamento fungicida e, as sementes de soja peliculizadas e tratadas com fungicida, podem ser armazenadas por até 60 dias.

Desta forma, o presente trabalho teve como objetivo verificar os efeitos da peliculização, tratamento fungicida e inseticida, sobre a qualidade fisiológica de sementes de híbridos de milho, durante o armazenamento.

\section{MATERIAL E MÉTODOS}

O trabalho foi conduzido no Laboratório de Análise de Sementes do Departamento de Agricultura e no Laboratório de Patologia de Sementes do Departamento de Fitopatologia da Universidade Federal de Lavras (UFLA), MG.

Para instalação dos experimentos, sementes dos híbridos AG9010 e AG122 foram tratadas ou não com inseticida carbofuran, de nome comercial Furazin 310 TS (dosagem de 1,5 L/100 kg de sementes), e em mistura com fungicida fludioxonil, de nome comercial Maxin (dosagem $100 \mathrm{~mL} / 100 \mathrm{~kg}$ de sementes). Em parte das sementes de cada tratamento os produtos foram diluídos com os polímeros 1519 na dosagem de $50 \mathrm{~mL} / 100 \mathrm{~kg}$ de sementes e 1080, na dosagem de $100 \mathrm{~mL} / 100 \mathrm{~kg}$ de sementes, e na outra parte os produtos foram diluídos em água.

Posteriormente, as sementes foram acondicionadas em embalagens de papel multifoliado e armazenadas durante seis meses sob condições ambientais, sendo que, a qualidade fisiológica e sanitária das sementes foram avaliadas antes e após o armazenamento.

As determinações de laboratório utilizadas foram:

Teor de água das sementes: foi determinado pelo método da estufa a $105^{\circ} \mathrm{C}$ por 24 horas, sendo utilizadas duas repetições de 50 sementes, por tratamento (BRASIL, 1992).

Determinação de sementes infestadas: duas subamostras de 100 sementes de cada tratamento foram embebidas em água durante 24 horas à temperatura ambiente e, posteriormente, seccionadas no sentido longitudinal, avaliando a presença de insetos, larvas, ovos ou sementes perfuradas por caruncho.

Teste de germinação: foi realizado segundo as Regras para Análise de Sementes - RAS (BRASIL, 1992), por meio da semeadura de 200 sementes por tratamento, divididas em quatro repetições de 50 sementes, em rolo de papel toalha germitest umedecido com água. Os rolos foram mantidos em germinador à temperatura de $25^{\circ} \mathrm{C}$ por cinco dias, quando foi realizada a avaliação. Os resultados foram expressos em porcentagem de plântulas normais.

Teste de frio: a semeadura foi realizada em bandejas plásticas contendo como substrato areia + solo na proporção 2:1, sendo o solo proveniente de área cultivada com milho. A umidade do substrato foi ajustada para $70 \%$ da capacidade de retenção de água, conforme prescrições da International Seed Test Association (ISTA, 1995). Foram utilizadas quatro repetições de 50 sementes por tratamento. Após a semeadura, as bandejas foram colocadas em câmara fria a $10^{\circ} \mathrm{C}$ por sete dias e, posteriormente, transferidas para câmara de crescimento vegetal à temperatura de $25^{\circ} \mathrm{C}$,

Ciênc. agrotec., Lavras, v. 29, n. 6, p. 1201-1208, nov./dez., 2005 
em regime alternado de luz e escuro (12 horas). Após sete dias nessas condições foi avaliado o número de plântulas normais emergidas.

Teste de emergência em bandeja: a semeadura foi realizada em bandejas plásticas contendo como substrato solo + areia na proporção 2:1. Foram utilizadas quatro repetições de 50 sementes por tratamento. Após a semeadura, as bandejas foram mantidas em câmara de crescimento vegetal à temperatura de $25^{\circ} \mathrm{C}$, em regime alternado de luz e escuro (12 horas). A partir da emergência da primeira plântula foram realizadas avaliações diárias, computando-se o número de plântulas emergidas até a estabilização. Foram considerados a porcentagem de plântulas normais aos 14 dias e também o índice de velocidade de emergência, determinado segundo fórmula sugerida por Krzyzanowski et al. (1999).

Teste de sanidade: as sementes foram incubadas em placas de Petri de $15 \mathrm{~cm}$ contendo três folhas de papel de filtro umedecidos com água. Foram utilizadas 25 sementes de cada tratamento por placa, num total de oito repetições. As placas permaneceram 24 horas em temperatura ambiente e, posteriormente, foram mantidas por 24 horas à temperatura de $-20^{\circ} \mathrm{C}$ (MACHADO, 1988). Em seguida, as placas com as sementes foram incubadas à temperatura de $20^{\circ} \mathrm{C}$ sob regime de 12 horas de luz e 12 horas de escuro, onde permaneceram por cinco dias para então serem avaliadas quanto à presença de patógenos.

Para os testes utilizados na avaliação da qualidade fisiológica das sementes, o delineamento experimental utilizado foi o inteiramente casualizado, em esquema fatorial $3 \times 3 \times 2$, sendo os fatores: produto fitossanitário (sementes tratadas com Furazin, Furazin+Maxim e sem tratamento), peliculização (polímero 1519, polímero 1080 e sem película) e período de armazenamento (zero e seis meses).

As análises estatísticas dos ensaios foram realizadas utilizando o pacote computacional SISVAR (FERREIRA, 2000). As médias entre os tratamentos foram comparadas pelo teste de Tukey, ao nível de 5\% de probabilidade.

\section{RESULTADOS E DISCUSSÃO}

Após submeter os dados à análise de variância, observou-se, para o híbrido AG9010, efeito significativo para épocas de armazenamento, nos testes de germinação e de frio, produto fitossanitário, no teste de germinação, e a interação produto fitossanitário $\mathrm{x}$ polímeros $\mathrm{x}$ épocas, pelo índice de velocidade de emergência. Já para o híbrido AG122 foram significativas apenas as diferenças dentro do fator produto fitossanitário, no teste de germinação, e a interação produto fitossanitário x polímeros x épocas, no índice de velocidade de emergência. Não houve efeito significativo em nenhuma das fontes de variação, em ambos os híbridos, para a porcentagem de emergência em bandeja e número de sementes infestadas.

Pelos resultados de porcentagem de germinação de sementes do híbrido AG9010, tratadas ou não com inseticida e inseticida+fungicida (Tabela 1), pôde-se verificar que as sementes submetidas ao tratamento fitossanitário apresentaram uma redução no número de plântulas normais, indicando um provável efeito fitotóxico dos produtos sobre as sementes. Deve-se ressaltar, que as sementes apresentavam alta qualidade inicial e que a redução na porcentagem de germinação das sementes tratadas foi de apenas $2 \%$, indicando a possibilidade de uso destes produtos para a proteção das sementes.

TABELA 1 - Resultados médios de porcentagem de germinação, provenientes de sementes de milho do híbrido AG9010, tratadas ou não com Furazin ou Furazin+Maxin, durante o armazenamento. UFLA, Lavras - MG, 2004.

\begin{tabular}{cc}
\hline Produto fitossanitário & \% Média de germinação \\
\hline Furazin & $93 \mathrm{~b}$ \\
Furazin+Maxin & $93 \mathrm{~b}$ \\
Sem & $95 \mathrm{a}$ \\
\hline
\end{tabular}

Médias seguidas das mesmas letras não diferem entre si pelo teste de Tukey a 5\% de probabilidade.

Durante o armazenamento das sementes de milho do híbrido AG9010, observou-se, por meio dos resultados médios de porcentagem de germinação, que as sementes avaliadas antes do armazenamento apresentaram porcentagem de germinação (97\%) significativamente superior, pelo teste de $\mathrm{F}$ a $5 \%$ de probabilidade, àquelas avaliadas após este período (91\%), em conseqüência do processo natural de deterioração das mesmas. No entanto, verificou-se que, mesmo após seis meses de armazenamento as sementes mantiveram uma porcentagem de germinação acima do estabelecido para a comercialização que é de $85 \%$ (BRASIL, 1985).

Os mesmos resultados observados no teste de germinação para as sementes do híbrido AG9010, antes e após o armazenamento, também foram obtidos no teste de frio, no entanto a redução na porcentagem de plântulas 
normais, após o estresse causado pelas condições do teste e pelas condições de armazenamento, foi de apenas $1 \%$, sendo que, antes do armazenamento as sementes apresentavam 98\% de plântulas normais. Assim, verificouse que as sementes, mesmo após seis meses de armazenamento, mantiveram alto vigor, quando comparadas com aquelas não armazenadas, confirmando a viabilidade do armazenamento, por até seis meses, de sementes de milho que apresentem alta qualidade fisiológica inicial. Nota-se que o percentual de germinação das sementes tanto antes como depois do armazenamento foi menor do que o vigor pelo teste de frio, isto provavelmente está relacionado com o alto índice de sementes contaminadas por Fusarium, pois as condições do teste de germinação são favoráveis para o desenvolvimento desse fungo, o que não acontece nas condições do teste de frio, conforme relatado por Oliveira (1997) e Pinho (1991).

Pelos resultados de índice de velocidade de emergência para as sementes de milho do híbrido AG9010 (Tabela 2), nota-se que não houve diferenças significativas no índice quando as sementes foram analisadas antes do armazenamento, no entanto, observa-se que o polímero
1080, associado ao inseticida, promoveu uma redução significativa na velocidade de emergência das sementes após o armazenamento. Este mesmo resultado foi também verificado para as sementes não tratadas com produto fitossanitário, porém com aquelas que foram peliculizadas com polímero 1519. Essa redução na velocidade de emergência pode ter ocorrido devido à restrição de oxigênio, promovida pela película, pois de acordo com Duan \& Burris (1997), os polímeros utilizados na peliculização podem restringir a entrada de água e ou oxigênio pela semente.

Pelos resultados de porcentagem de germinação para as sementes do híbrido AG122 (Tabela 3), nota-se que o comportamento foi semelhante àqueles obtidos com sementes do híbrido AG9010, sendo que o produto inseticida ou inseticida+fungicida causou significativa redução na porcentagem de plântulas normais. A diferença entre as médias das sementes tratadas ou não foi de 1 a $2 \%$, indicando um baixo nível de toxidez, pois o percentual de germinação das sementes que foram tratadas permaneceu alto, $97 \mathrm{e} 98$, para aquelas tratadas com inseticida e com inseticida+fungicida, respectivamente.

TABELA 2 - Resultados médios de índice de velocidade de emergência, provenientes de sementes de milho do híbrido AG9010, tratadas ou não com Furazin ou Furazin+Maxin, com e sem polímeros, antes e após seis meses de armazenamento. UFLA, Lavras - MG, 2004.

\begin{tabular}{clccc}
\hline Épocas (meses) & Polímeros & \multicolumn{3}{c}{ Produto fitossanitário } \\
\cline { 3 - 5 } & & Furazin & Furazin+Maxin & Sem \\
\hline \multirow{2}{*}{ Zero } & 1519 & 16,24 a A & 16,08 a A & 15,91 a A \\
& 1080 & 16,04 a A & 16,28 a A & 15,94 a A \\
& Sem & 15,94 a A & 15,90 a A & 16,29 a A \\
\hline \multirow{2}{*}{ Seis } & 1519 & 16,40 a A & 16,31 a A & 14,43 b B \\
& 1080 & $15,07 \mathrm{~b} \mathrm{~B}$ & 16,07 a A & 16,35 a A \\
& Sem & 16,31 a A & 16,19 a A & 16,23 a A \\
\hline
\end{tabular}

Médias seguidas das mesmas letras minúsculas nas linhas ou maiúsculas nas colunas, para cada período de armazenamento, não diferem entre si pelo teste de Tukey a 5\% de probabilidade.

TABELA 3 - Resultados médios de porcentagem de germinação, provenientes de sementes de milho do híbrido AG122, tratadas ou não com Furazin ou Furazin+Maxin. UFLA, Lavras-MG, 2004.

\begin{tabular}{lc}
\hline Produto fitossanitário & \% Média de geminação \\
\hline Furazin & $97 \mathrm{~b}$ \\
Furazin+Maxin & $98 \mathrm{ab}$ \\
Sem & $99 \mathrm{a}$ \\
\hline
\end{tabular}

Médias seguidas das mesmas letras não diferem entre si pelo teste de Tukey a 5\% de probabilidade.

Ciênc. agrotec., Lavras, v. 29, n. 6, p. 1201-1208, nov./dez., 2005 
$\mathrm{Na}$ Tabela 4 estão os resultados do índice de velocidade de emergência para sementes de milho do híbrido AG122. Observa-se que, as sementes recém tratadas com inseticida utilizando o polímero 1519 , apresentaram um menor índice em relação aquelas sem polímero ou com o polímero 1080. No entanto, após o armazenamento o menor índice para sementes que foram tratadas apenas com inseticida ocorreu quando se aplicou o polímero 1080 e quando se utilizou a mistura, inseticida+fungicida, sendo que o menor índice foi obtido com sementes peliculizadas com o polímero 1519 . Notase, pelos resultados obtidos, que o polímero 1080 proporcionou um índice de velocidade de emergência maior, em relação às sementes não peliculizadas ou com polímero 1519 , quando as sementes não foram tratadas. Ressaltando que a interação polímero e tratamento químico podem promover algum efeito prejudicial na velocidade de emergência das plântulas, principalmente se as sementes tiverem baixa qualidade inicial.

A avaliação da qualidade sanitária das sementes dos híbridos AG9010 (Tabela 5) e AG122 (Tabela 6) revelou uma alta incidência, principalmente antes do armazenamento, de Fusarium, Penicillium e Cladosporium, no entanto com baixa patogenicidade, conforme resultados de teste padrão de germinação, de frio e índice de velocidade de emergência.
Provavelmente, esses fungos estavam contaminando superficialmente as sementes, pois pelo exame visual as sementes não possuíam danos mecânicos e pelos resultados dos testes fisiológicos, apresentavamse com alta qualidade, mesmo após seis meses de armazenamento.

De modo geral, ao longo do armazenamento das sementes, houve uma redução do percentual de Fusarium para ambos os híbridos. Esses resultados corroboram com aqueles encontrados por Carvalho (1992), Oliveira (1997) e Pinho (1991) em sementes de milho. Também o percentual de Cladosporium e Penicillium foi reduzido ao longo do armazenamento.

Observou-se, ainda, que o tratamento com produtos fitossanitários, inseticida e inseticida+fungicida, foi responsável pela redução acentuada no percentual desses fungos antes e durante o armazenamento, o que ressalta a importância deste tratamento para o armazenamento de sementes de milho. Vale ressaltar, ainda, que o efeito do tratamento das sementes ocorreu independentemente da peliculização, indicando que a peliculização não afeta a ação do fungicida. Resultados semelhantes foram obtidos por Rivas et al. (1998), os quais relatam que não houve alteração na ação do fungicida Captan quando associado aos polímeros que foram estudados.

TABELA 4 - Resultados médios de índice de velocidade de emergência, provenientes de sementes de milho do híbrido AG122, tratadas ou não com Furazin ou Furazin+Maxin, com e sem polímeros, antes e após seis meses de armazenamento. UFLA, Lavras - MG, 2004.

\begin{tabular}{ccccc}
\hline Épocas (meses) & Polímeros & \multicolumn{3}{c}{ Produto fitossanitário } \\
\cline { 2 - 5 } & & Furazin & Furazin+Maxin & Sem \\
\hline \multirow{2}{*}{ Zero } & 1519 & $14,93 \mathrm{~b} \mathrm{~B}$ & $16,08 \mathrm{a} \mathrm{A}$ & $15,38 \mathrm{~b} \mathrm{~B}$ \\
& 1080 & $15,84 \mathrm{a} A$ & $15,94 \mathrm{a} \mathrm{A}$ & $16,08 \mathrm{a} \mathrm{A}$ \\
& Sem & $16,11 \mathrm{a} \mathrm{A}$ & $15,91 \mathrm{ab} \mathrm{A}$ & $15,42 \mathrm{~b} \mathrm{~B}$ \\
\hline \multirow{2}{*}{ Seis } & 1519 & $15,56 \mathrm{a} \mathrm{A}$ & $12,80 \mathrm{~b} \mathrm{~B}$ & $12,88 \mathrm{~b} \mathrm{C}$ \\
& 1080 & $13,29 \mathrm{c} \mathrm{B}$ & $14,38 \mathrm{~b} \mathrm{~A}$ & $15,17 \mathrm{a} \mathrm{A}$ \\
& Sem & $15,24 \mathrm{a} \mathrm{A}$ & $14,93 \mathrm{ab} \mathrm{A}$ & $14,42 \mathrm{~b} \mathrm{~B}$ \\
\hline
\end{tabular}

Médias seguidas das mesmas letras minúsculas nas linhas ou maiúsculas nas colunas, para cada período de armazenamento, não diferem entre si pelo teste de Tukey a $5 \%$ de probabilidade. 


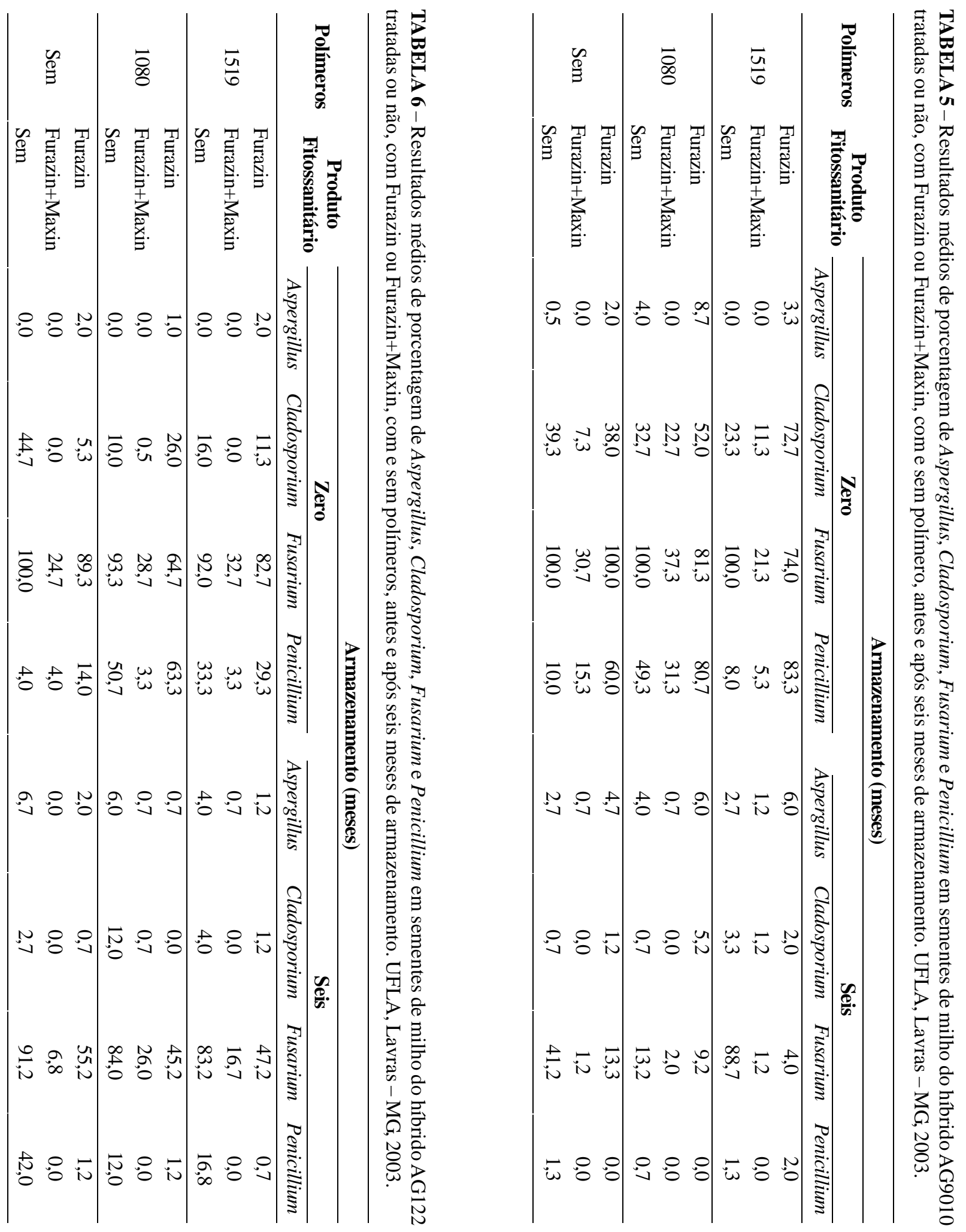




\section{CONCLUSÕES}

a) A peliculização não afetou a qualidade fisiológica das sementes de milho e não interfere no efeito do tratamento químico em sementes com alta qualidade inicial;

b) Aplicação de Furazin + Maxin, sobre sementes de milho, é tecnicamente viável;

c) Sementes de milho tratadas com Furazin + Maxin podem ser armazenadas por seis meses, sem que haja comprometimento de sua qualidade fisiológica.

\section{REFERÊNCIAS BIBLIOGRÁFICAS}

ALVES, M. C. S.; GUIMARÃES, R. M.; CLEMENTE, F. M. V. T.; GONÇALVES, S. M.; PEREIRA, S. P.; OLIVEIRA, S. Germinação e vigor de sementes de feijoeiro (Phaseolus vulgaris L.) peliculizadas e tratadas com fungicida. In: CONGRESSO BRASILEIRO DE SEMENTES, 13., 2003, Londrina. Informativo ABRATES, Londrina, v. 13, n. 3, 2003.

BARROS, R. G.; BARRIGOSSI, J. A. F.; COSTA, J. L. S. Compatibilidade de fungicidas, inseticidas e micronutrientes, associados ou não a um polímero no tratamento de sementes de soja (Glycine max (L.) Merrill). In: CONGRESSO BRASILEIRO DE SOJA E MERCOSOJA, 2., 2002, Londrina. Resumos... Londrina: EMBRAPA Soja, $2002.393 \mathrm{p}$.

BRASIL. Minsitério da Agricultura e Reforma Agrária. Regras para análise de sementes. Brasília, 1992. 365 p.

BRASIL. Ministério da Agricultura. Normas, padrões e procedimentos para a produção de sementes básicas, certificadas e fiscalizadas. 2. ed. Belo Horizonte, 1985. 110 p.

CARVALHO, M. L. M. Refrigeração e qualidade de sementes de milho armazenadas em pilha com diferentes embalagens. 1992. 98 f. Tese (Doutorado em Fitotecnia) Escola Superior de Agricultura "Luiz de Queiroz", Piracicaba, 1992.

CLEMENTE, F. M. V. T.; OLIVEIRA, J. A.; ALVES, A. C. S.; GONÇALVES, S. M.; PEREIRA, S. P.; OLIVEIRA, S. Peliculização associada a doses de fungicida na qualidade fisiológica de sementes do feijoeiro (Phaseolus vulgaris L.). In: CONGRESSO BRASILEIRO DE SEMENTES, 13., 2003, Londria. Informativo ABRATES, Londrina, v. 13, n. 3, 2003.
DUAN, X.; BURRIS, J. S. Film coating impairs leaching of germination inhibitors in sugar beet seed. Crop Science, Madison, v. 37, p. 515-520, 1997.

FERREIRA, D. F. Análises estatísticas por meio do SISVAR para Windows ${ }^{\grave{O}}$ versão 4.0. In: REUNIÃO ANUAL DA REGIÃO BRASILEIRA DA SOCIEDADE INTERNACIONAL DE BIOMETRIA, 45., 2000, São Carlos, SP. Programas e Resumos... São Carlos: UFSCAR, 2000. p. 235.

HENNING, A. A.; FRANÇA NETO, J. B.; KRZYZANOWSKY, F. C.; COSTA, N. P. Avaliação de corantes, polímeros, pigmentos e fungicidas para o tratamento de sementes de soja. In: CONGRESSO BRASILEIRO DE SEMENTES, 13., 2003, Londrina. Informativo ABRATES, Londrina, v. 13, n. 3, 2003.

INTERNATIONAL SEED TEST ASSOCIATION. Handbook of vigour test methods. 3. ed. [S.I.], 1995. 117 p.

KRZYZANOWSKI, F. C.; VIEIRA, R. D.; FRANÇA NETO, J. B. (Eds.). Vigor de sementes: conceitos e testes. Londrina: ABRATES, 1999.

LIMA, L. B.; MASETTO, T. E.; CARVALHO, M. L. M.; OLIVEIRA, J. A. Tratamento fungicida e peliculização de sementes de tomate. In: CONGRESSO BRASILEIRO DE SEMENTES, 13., 2003, Londrina. Informativo ABRATES, Londrina, v. 13, n. 3, 2003a.

LIMA, L. B.; SILVA, P. A.; GUIMARÃES, R. M.; OLIVEIRA, J. A. Peliculização e tratamento qímico de sementes de algodão. In: CONGRESSO BRASILEIRO DE SEMENTES, 13., 2003, Londrina. Informativo ABRATES, Londrina, v. 13, n. 3, 2003b.

LIMA, L. B.; TRENTINI, P.; MACHADO, J. C.; OLIVEIRA, J. A. Tratamento qímico de sementes de soja visando ao controle de Phomopsis sojae associado a semente e Rhizoctonia solani no solo. In: CONGRESSO BRASILEIRO DE SEMENTES, 13., 2003, Londrina. Informativo ABRATES, Londrina, v. 13, n. 3, $2003 c$.

MACHADO, J. C. Patologia de sementes: fundamentos e aplicações. Brasília: MEC/ESAL/FAEPE, 1988. 107 p. 
MAUDE, R. Progressos recentes no tratamento de sementes. In: SEMINÁRIO PANAMERICANO DE SEMILLAS, 15., 1996, Gramado, RS. Memórias... Passo Fundo: CESM, 1998. p. 99-106.

OLIVEIRA, J. A. Efeito do método de colheita e do tipo de armazenamento na qualidade de sementes de milho. 1997. 134 f. Tese (Doutorado em Fitotecnia) - Universidade Federal de Lavras, Lavras, 1997.

PINHO, E. V. R. von. Influência do tratamento da semente e do tratamento fungicida e inseticida na preservação da qualidade de sementes de milho durante 0 armazenamento e seu comportamento no campo. 1991. 112 f. Dissertação (Mestrado em Fitotecnia) - Universidade Federal de Lavras, Lavras, 1991.

RIVAS, B. A.; McGEE, D. C.; BURRIS, J. S. Tratamiento de semillas de maiz con polimeros para el control de Pythium spp. Fitopatologia Venezuelana, [S.1.], v. 11, p. 10-15, 1998.
ROBANI, H. Film coating horticultural seed. Hort Technology, [S.1.], v. 4, p. 104-105, 1994.

SAMPAIO, N. V.; SAMPAIO, T. G. Sementes: com as cores da eficiência. A Granja do Ano, Porto Alegre, n. 12, p. 16-18, 1998.

SILVEIRA, S. Recobertura como medida para proteção da semente. Seed News, Pelotas, n. 5, p. 34-35, 1998.

SMITH, S. Colorants and polymers: there is a difference. Seed World, Chicago, v. 135, n. 13, p. 26-27, 1997.

TAYLOR, A. G.; ALLEN, P. S.; BENNETT, M. A.; BRADFORD, K. J.; BURRIS, J. S.; MISRA, M. K. Seed enhancements. Seed Science Research, [S.1.], v. 8, p. 245-256, 1998.

TAYLOR, A. G.; KWIATKOWSKI, J.; BIDDLE, A. J. Polymer film coating decease water uptake and water vapour movement into seeds and reduce imbibitional chilling injury. In: INTERNATIONAL SYMPOSIUM SEED TREATMENT CHALLENGES AND OPPORTUNITIES, 2001. Proceedings... [S.1.: s.n.], 2001. p. 215-220. 